BMC

Evolutionary Biology

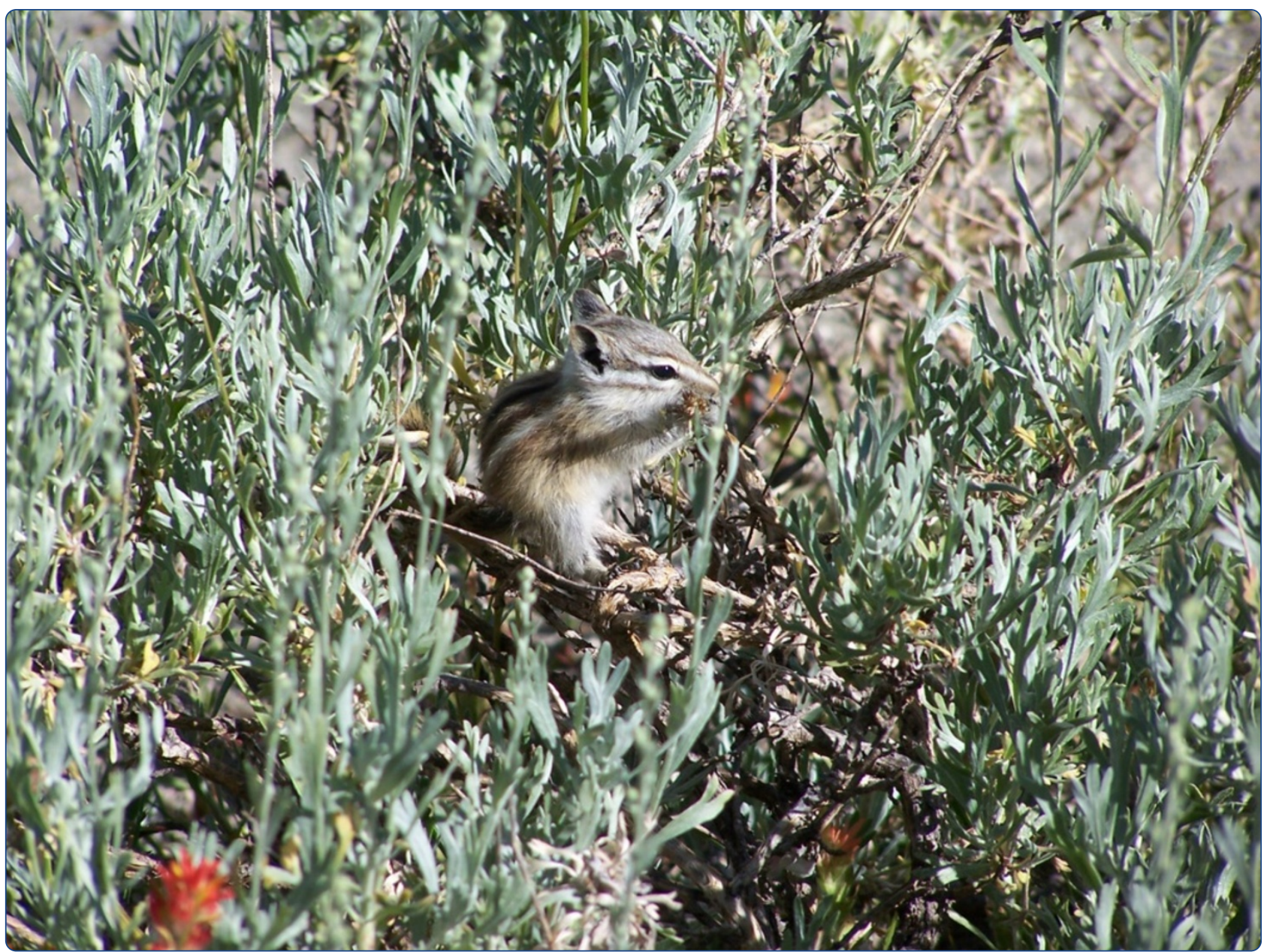

\title{
Diversification of the Alpine Chipmunk, Tamias alpinus, an alpine endemic of the Sierra Nevada, California
}

Rubidge et al. 


\title{
Diversification of the Alpine Chipmunk, Tamias alpinus, an alpine endemic of the Sierra Nevada, California
}

\author{
Emily M Rubidge ${ }^{1,2^{*}}$, James $L$ Patton ${ }^{1}$ and Craig Moritz ${ }^{3}$
}

\begin{abstract}
Background: The glaciation cycles that occurred throughout the Pleistocene in western North America caused frequent shifts in species' ranges with important implications for models of species divergence. For example, long periods of allopatry during species' range contractions allowed for the accumulation of differences between separated populations promoting lineage divergence. In contrast, range expansions during interglacial periods may have had homogenizing effects via increased gene flow following secondary contact. These range dynamics are particularly pronounced in the Sierra Nevada, California, given the complex topography and climatic history of the area, thus providing a natural laboratory to examine evolutionary processes that have led to the diversity patterns observed today.
\end{abstract}

Results: Here we examined the role of late Pleistocene climate fluctuations on the divergence of the Sierra Nevada endemic Alpine Chipmunk (Tamias alpinus) from its sister taxon, western populations of the Least Chipmunk (T. minimus) from the Great Basin. We used one mitochondrial gene (cytochrome b) and 14 microsatellite loci to examine the evolutionary relationship between these species. Mitochondrial sequence data revealed that $T$. alpinus and T. minimus populations share mitochondrial haplotypes with no overall geneaological separation, and that diversity at this locus is better explained by geography than by species' boundaries. In contrast, the microsatellite analysis showed that populations of the same species are more similar to each other than they are to members of the other species. Similarly, a morphological analysis of voucher specimens confirmed known differences in morphological characters between species providing no evidence of recent hybridization. Coalescent analysis of the divergence history indicated a late Pleistocene splitting time ( 450 ka) and subsequent, though limited, gene flow between the two lineages.

Conclusions: Our results suggest that the two species are distinct and there is no contemporary introgression along their geographic boundary. The divergence of $T$. alpinus during this time period provides additional evidence that Pleistocene glacial cycles played an important role in diversification of species in Sierra Nevada and North America in general.

\section{Background}

Understanding processes that promote and maintain biodiversity is a key goal of evolutionary biology. Divergent natural selection resulting from resource heterogeneity and competitive interactions can drive population divergence and speciation [1,2]. Nonadaptive divergence,

\footnotetext{
* Correspondence: erubidge@gmail.com

${ }^{1}$ Museum of Vertebrate Zoology, 3101 Valley Life Sciences Building University

of California, Berkeley, California 94720-3160, USA

${ }^{2}$ Royal British Columbia Museum, 675 Belleville Street, Victoria, British

Columbia V8W 9W2, Canada

Full list of author information is available at the end of the article
}

operating via genetic drift due to isolation and founder effects, may also play a significant role in generating patterns of species diversity. Furthermore, hybridization (or reticulate evolution) during and subsequent to speciation can add novel genetic diversity to diverging lineages and affect the course of adaptive divergence [3-5]. The cyclical Pleistocene glacial and interglacial episodes have shaped the genetic architecture of taxa across the globe, as retraction to refugia facilitated the formation of distinct evolutionary lineages within species [6,7] through both vicariant processes and shifting the spatial distribution 
and extent of ecological gradients. Recurrent fragmentation and expansion provides opportunities for initial divergence, repeated secondary contact, hybridization, and demographic fluctuation [8].

Range dynamics and the complex geological and climatic history of the Sierra Nevada, California has shaped diversity patterns of the central-western United States over the time span of most, if not all, extant species. The late Pleistocene in particular was a time of drastic climatic fluctuations in the Sierra Nevada [9] and the adjacent Great Basin and Mohave biomes [10] and thus a period linked to both intra- and interspecific diversification in many taxa (e.g., [11-14]).

\section{The physical setting: Sierra Nevada and the Great Basin}

The Sierra Nevada and the adjacent Great Basin is a biologically diverse region with a rich glacial history [10,15-17]. The Sierra Nevada are a narrow, elongated, topographically complex, high, and relatively young mountain range that spans about $640 \mathrm{~km}$ from north to south and $110 \mathrm{~km}$ from west to east, and contains the highest peak in the continental United States (Mt. Whitney, 4,421 m). Given the steep elevational gradient on the east side of the Sierra Nevada, the mountain range casts a major rain shadow affecting the climate and ecology of the adjacent central Great Basin of the intermountain west. The Great Basin consists of over $10,500 \mathrm{~km}^{2}$ of valleys, basins, lakes and mountain ranges with extreme elevational relief throughout the region. It contains the lowest point in North America (-86 m, in Death Valley, California) as well as one of the highest (4342 m, White Mountain Peak, CA) [17]. The complexity of small mammal distributions in relation to the high environmental diversity in the Great Basin, have made this region a focus for biogeographic research (e.g., [17-20]).

The interactions between Sierra Nevada with the Great Basin and Mojave Desert biomes during the cyclical glaciations of the Pleistocene created areas of recurrent isolation and secondary contact within and between species. The Sierra Nevada has experienced at least six cyclical episodes of glacial expansion and retreat, both regional and local in extent, beginning in the early Pleistocene $(1.65 \pm 0.7 \mathrm{mybp})$, with the most recent advance around $3.5 \mathrm{kbp}$ [21], as well as three or more neoglacial advances ending with termination of the Little Ice Age, which spanned 1350 to 1850 AD [22]. These episodes are intertwined with a similarly complex history of volcanism along the eastern flank of the range over the same time period [23]. Few glaciers remain in the Sierra Nevada today, with most having shrunk by greater than half in mass and aerial extent within the latter half of the $20^{\text {th }}$ century [24]. This complex glacial history and associated range dynamics and steep environmental gradients in the Sierra Nevada and the adjacent Great Basin provide a natural laboratory to examine species histories including the combined effects of range fluctuations, oscillations between isolation and introgression, and adaptive divergence across environmental gradients (e.g., $[25,26])$.

\section{Chipmunk diversity in western North America}

The biogeographic history, radiation, and evolutionary relationships of western North American chipmunks are complex and include several instances of historical introgression among species [27-32]. Chipmunk diversity is centered in western North America with 23 species $[28,33]$ and diversification has been linked to shifting ranges resulting from climatic cycles and subsequent shifts in habitat preference resulting from interspecific competition and niche partitioning over elevational gradients [34-36]. In this study, we examine the evolutionary history of the Alpine Chipmunk, Tamias alpinus, a narrow high-elevation endemic, relative to its widespread sister species, the Least Chipmunk, Tamias minimus.

The divergence history of $T$. alpinus is not well understood; however, recent work has shown that $T$. alpinus and T. minimus are paraphyletic [32]. T. minimus represents a species complex and this study focuses on the western segment of the species, geographically adjacent to the range of T. alpinus. Previous work by Reid et al. [32] included geographically (and taxonomically) disparate sequences from T. minimus individuals from California, Nevada, Utah, Wyoming and Washington and clearly showed that $T$. alpinus is nested with western segments of T. minimus scrutator. Here, we focus on regions of allo/parapatry in the Sierra Nevada where these two species come into close proximity to better understand the evolutionary history of $T$. alpinus.

Our objective is to examine the relationship between $T$. alpinus and $T$. minimus, with the goal of gaining a better understanding of the evolutionary history of T. alpinus. More specifically, we focus on two questions 1) did T. alpinus diverge from $T$. minimus in association with late-Pleistocene glacial dynamics and 2) is there evidence for contemporary or historical introgression as reported in other species-pairs of chipmunks [30,31]. To address these questions we examine morphological characters and genetic variation and population structure at one mitochondrial gene and 14 microsatellite loci. Contrasting patterns of nucleotide variation in the mitochondrial genome with patterns of genetic variation at microsatellite markers gives us a picture of both historical and contemporary processes respectively. And although differences in morphological characters between species are well defined (see below), testing for morphological intermediacy in individuals in adjacent versus distant populations will help distinguish between genetic 
similarity due to recent speciation or similarity as a result of secondary contact and hybridization.

\section{Methods}

\section{Study species}

The $T$. minimus species complex contains 21 recognized subspecies [37] and is the most widely distributed Tamias species [38]. It occurs from western central Yukon Territory southward along the eastern base of the Rocky Mountains in British Columbia (BC) eastward throughout Canada's provinces, upper Michigan and Minnesota. It is also found throughout the Great Basin with disjunct populations further south in Arizona and New Mexico [37]. The subspecies, $T$. minimus scrutator, is the sister taxa to T. alpinus [32] and occurs across southeastern Oregon, south-central Washington, northern and central Nevada, western Utah, southwestern Idaho and NE California [39], mainly east of Sierras, with an isolated high elevation population at the southern terminus of the mountain range (Figure 1). For the purposes of this study, we will use T. minimus, to refer to the subspecies $T$. $m$. scrutator and specifically the Californian populations adjacent to T. alpinus (Figure 1).

T. alpinus is geographically restricted to the high elevations of the central to southern Sierra Nevada (Figure 1). Based on historical records and our own surveys, $T$. alpinus and $T$. minimus are allopatric throughout our study area. South of Yosemite, there are reported areas of sympatry in the central Sierra Nevada northwest of Bishop (D. Guiliani, pers. comm.), but none have been confirmed despite our targeted field surveys between 2009-2013. Collections made in 1911 in the southern Sierras recorded both species at the same locality (Little Brush Meadow, Tulare Co.), but apparently at different elevations $(9750 \mathrm{ft}$ for $T$. minimus and 10,000 ft for T. alpinus; field notes of the collectors, H. A. Carr and W. P. Taylor, MVZ archives). This difference in elevation signals distinctly different habitats,

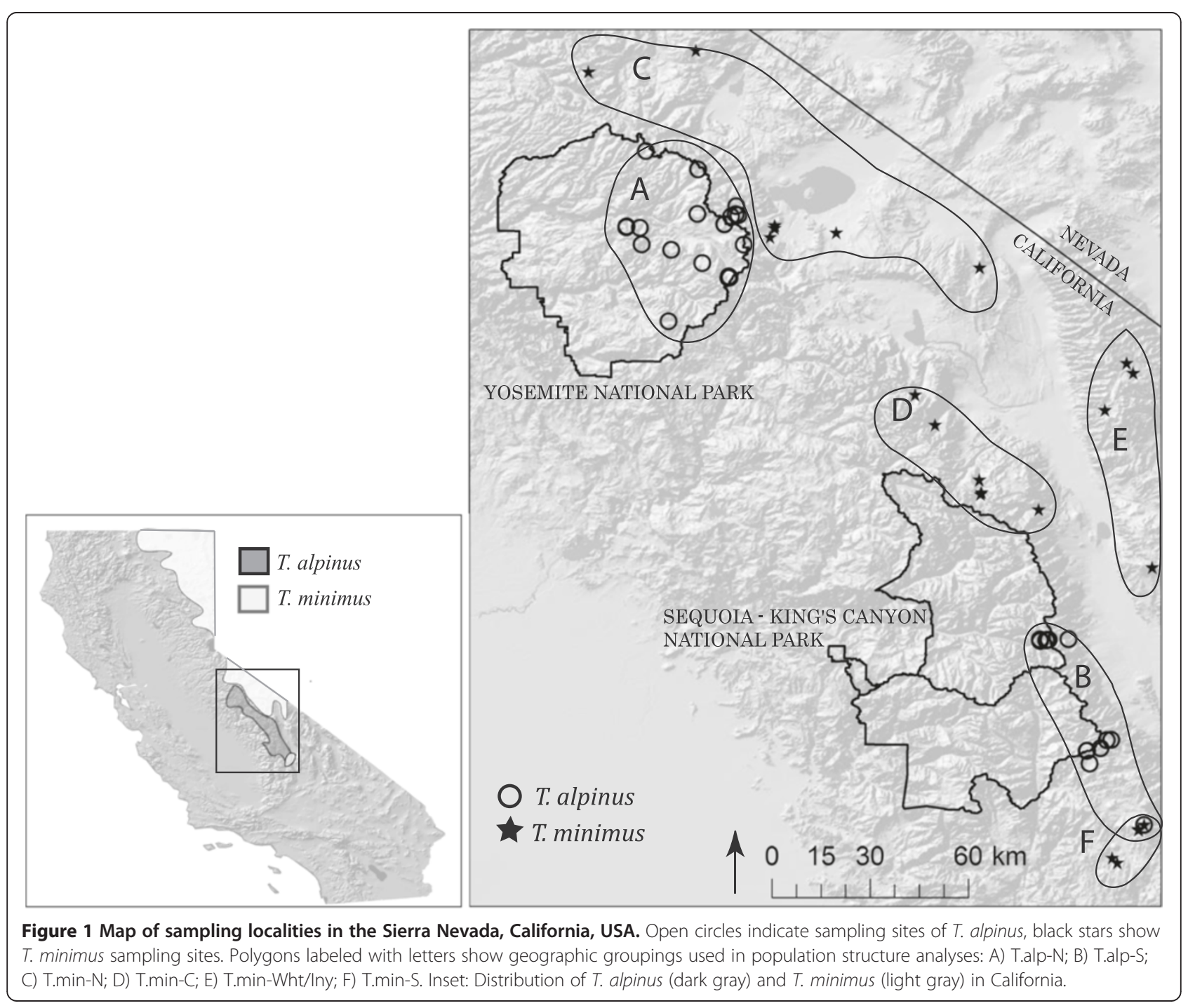


where lodgepole pine (Pinus contorta) with a sagebrush understory at the lower elevation is replaced by scattered foxtail pine (Pinus balfouriana) and arctic-alpine forbs near treeline. These habitats characterize the ecological distribution of the two species in other areas where their ranges come into close proximity.

The two species differ in morphology and habitat preferences. T. minimus, among other characters, is smaller in body mass, has a longer tail, shorter ears and darker coloration than T. alpinus [39] and has a different bacular (penis bone) morphology [37,40]; more specific details of these differences are summarized in Additional file 1: Table S1. In California, T. minimus is found in arid sagebrush habitat that ranges in elevation from $1500 \mathrm{~m}$ to above $3000 \mathrm{~m}$ in the Sierra Nevada and mountains to the immediate east (e.g., Sweetwater, White, and Inyo ranges). T. alpinus is restricted to the alpine zone of the Sierra Nevada at and above tree-line (2950 to $4100 \mathrm{~m}$ ) where it occupies open granite habitat, meadow edges and talus slopes [39,41].

\section{Study site and samples}

The study area is the central to southern Sierra Nevada, CA, USA, which includes the entire known range of $T$. alpinus and that of $T$. minimus to the immediate east and north (Figure 1). A total of 341 chipmunks were included in this study. The majority of samples were collected between 2003-2009, however 14 samples were taken from museum skins that were collected between 1911-1916 and housed in the Museum of Vertebrate Zoology (MVZ) at the University of California, Berkeley. For the samples collected between 2003-2009, we livetrapped animals using Sherman traps at 62 locations between 2003-2009 (Figure 1). We used non-lethal sampling (ear clips) and collected vouchered specimens, including liver samples, now catalogued in the MVZ (see Additional file 2: Table S4 for MVZ catalogue numbers and locations). Chipmunks collected in areas of potential sympatry were identified to species in the field based on distinct morphological differences including body size, pelage color, and ear and tail length. More rigorous morphological measurements on collected specimens were conducted in the lab to better document species-specific morphological differences. Sample collection was approved by the Animal Care and Use Committee (Protocol \#R304-0509) at the University of California, Berkeley.

\section{Morphological methodology and analyses}

Despite well-characterized differences between species, these two taxa share a close genetic legacy, and in order to distinguish between the possibility that this similarity resulted from recent common ancestry versus reticulation subsequent to divergence (e.g., $[30,31,42]$ ), we exa- mined the morphology of specimens taken from geographically adjacent versus distant localities to test for morphological intermediacy, using the same geographic groupings in the molecular comparison (Figure 1). We examined three data sets separately. The first containing external body metrics that have been used to separate the two species including: a) color and color pattern (b) tail length and bushiness; (c) ear length $(\mathrm{N}=36$ and 129 for $T$. alpinus and T. minimus respectively). The second dataset was based on comparing bacular dimensions $(\mathrm{N}=15$ and 33; shaft length, mid-shaft height, tip height, tip angle, and keel breadth following [43]). The third and final dataset examined craniodental features measured from preserved skulls $(\mathrm{N}=161$ and 159). We used separate conical variate analyses (CVA; JMP 5.1.1 statistical software) for each dataset, which generates a classification matrix of group membership, with individual posterior probabilities, based on multivariate discriminant functions.

\section{DNA extraction, sequencing, and microsatellite genotyping \\ DNA extraction}

To extract DNA from the liver or ear tissue samples, we used the standard Qiagen DNAeasy kit following the manufacturer's protocol (Qiagen). Tissue extractions were eluted in a total of $400 \mu \mathrm{l} \mathrm{AE}$ buffer. All extractions and PCR set-up on the 14 skin samples from museum specimens ("historical" samples) were conducted in a separate laboratory devoted to ancient DNA research. We followed the museum skin DNA extraction protocol described in Mullen and Hoekstra [44]. After removing an approximately $3 \mathrm{~mm} \times 3 \mathrm{~mm}$ square piece of skin from the lower lip, we placed the sample in $95 \%$ ethanol and refreshed the ethanol roughly every 3 hours over a 24-hour period to wash the sample of salts and PCR inhibitors. Following these washes, each skin sample was carefully removed of hair and shaved into smaller pieces with a scalpel and placed into a $1.5 \mathrm{ml}$ locking Eppendorf tube. Between each sample, the forceps and scalpel were washed in 10\% bleach, rinsed in 95\% ethanol and flamed to avoid cross contamination. We extracted DNA using a Qiagen DNeasy Tissue Extraction kit with the following modifications. First we diluted the $\mathrm{AE}$ Buffer to $1: 10$ in RNAse-free $\mathrm{H}_{2} \mathrm{O}$ and warmed it to $70^{\circ} \mathrm{C}$ prior to elution. Second, we applied two elutions of $50 \mu \mathrm{l}$ of warm 1:10 AE Buffer to the spin columns and allowed this elution step to incubate at room temperature for $5 \mathrm{~min}$ prior to the final spin. We conducted a negative extraction (sterilized forceps in extraction buffer) alongside all historical skin extractions. The negative extraction was run along with a negative PCR control in reactions to test for contamination between samples. 


\section{Mitochondrial DNA analysis}

An $801 \mathrm{bp}$ portion of the mitrochondrial gene, Cytochrome $\mathrm{b}($ cyt b), was amplified using universal mammal primers, MVZ05 \& MVZ16 [45]. We sequenced 139 T. alpinus and 107 T. minimus samples for a total dataset of 246 sequences. For the 14 historical samples, because the DNA was more degraded we were only able to amplify a fragment less than $400 \mathrm{bp}$. Therefore, we developed three pairs of genus specific primers to amplify shorter fragments that could be pieced together to complete a $780 \mathrm{bp}$ sequence for the historical DNA samples (Additional file 3: Table S2). To ensure the speciesspecific primers were not causing any irregularities in the sequences, we also used these primers on five modern DNA samples and compared the results with the sequences using the MVZ universal primer pair. The thermal cycler conditions for the mitochondrial PCRs were as follows: $94^{\circ} \mathrm{C}$ for $2 \mathrm{mins}, 35$ cycles of $94^{\circ} \mathrm{C}$ for 30 s, $47-50^{\circ} \mathrm{C}$ for $30 \mathrm{~s}, 72^{\circ} \mathrm{C}$ for $60 \mathrm{~s}$ and then a final extension at $72^{\circ} \mathrm{C}$ for 5 mins. Historical samples were sequenced in both the forward and reverse direction and PCR'd and sequenced at least twice to ensure repeatability of resulting sequence. Amplicons were sequenced on an ABI 3730 Capillary Sequencer (Applied Biosystems, Inc.). Resulting sequences were edited and aligned using Sequencher 4.8 (Gene Codes Corp.).

\section{Mitochondrial data analyses}

We used two approaches to estimate genealogical relationships. First, to estimate the phylogenetic relationships of haplotypes, we used the Bayesian approach implemented in MRBAYES 3.1.2 [46]. The best-fit model of nucleotide change was estimated using Akaike Information Criterion as implemented in jModeltest [47]. The model of sequence evolution ranked highest by AIC for the dataset was the Tamura-Nei model $(\operatorname{TrN}+\mathrm{I}+\Gamma)$ but because $\operatorname{TrN}$ is not an option in MrBayes, and this model is a special case of the general time reversible model (GTR) we used GTR $+\mathrm{I}+\Gamma$. We ran four MCMC chains for 3,000,000 generations with trees sampled every 300 generations. We assessed convergence by examining the standard deviation of split frequencies, which were $<0.01$ after $3 \times 10^{6}$ generations. A burn-in period of $10^{5}$ was discarded prior to calculating the consensus tree. Three individuals of the Panamint chipmunk (Tamias panamintinus) were used as an outgroup to T. alpinus and T. minimus [31]. Traditional phylogeny reconstruction approaches such as described above, however, make several assumptions that make them inaccurate at the population level. For example, they assume ancestral haplotypes are no longer present in the population. Therefore, our second approach was to use haplotype networks to estimate the genealogical relationship using the statistical parsimony approach [48] as implemented in the program TCS 2.1 [49].

Genetic variation among sequences within species was quantified as haplotype diversity $\left(\mathrm{h}_{\mathrm{d}}\right)$, and nucleotide diversity $\left(\theta_{\pi} \cdot \theta_{\mathrm{S}}\right)$. To quantify mtDNA differentiation between species and/or populations we calculated the average and the net number of nucleotide substitutions per site ( $D x y$ and $D a,[50])$. To visualize divergence patterns we clustered individuals by geography and species and used $D x y$ to produce a neighbour-joining tree in MEGA version 4 [51]. All diversity and distance calculations were estimated in program DNAsp version 5 [52]. We used an Analysis of Molecular Variance (AMOVA) implemented in the program ARLEQUIN [53] to examine the population structure of sequence diversity. F-statistic analogues $(\phi)$ were calculated to estimate the differentiation among groups $\left(\phi_{\mathrm{CT}}\right)$ among populations within groups $\left(\phi_{\mathrm{SC}}\right)$ and within populations $\left(\phi_{\mathrm{ST}}\right)$. Populations were grouped according to their species designation and sampling locality (Figure 1). We tested the statistical significance of the AMOVA with 10000 permutations and corrected the p-values associated with the $\phi$ values using Bonferroni correction for multiple tests. To test for historical population expansion or contraction in each species we calculated Tajima's D [54] and Fu's Fs statistic [55] and the 95\% confidence interval around these statistics using the bootstrap method (with no recombination) offered in DNAsp [53] with 5000 replicates.

\section{Microsatellite analyses}

We amplified the DNA at 14 microsatellite loci in T. alpinus and T. minimus (Loci names: EuAmMS26, EuAmMS37, EuAmMS41, EuAmMS86, EuAmMS94, AC A2, AC A101, AC A108, AC B12, AC B111, AC C2, AC C122, AC D107 and AC D115). The first five were taken from the literature [56], and the remaining nine were developed in T. alpinus. Primer sequences of all 14 loci are available in Additional file 3: Table S2. Reverse primers were fluorescently labeled with one of the following dyes: PET, NED, FAM, or HEX, forward primers were unlabeled. PCR reactions with a volume of $8.0 \mu \mathrm{l}$ contained reagents in the following concentrations: 0.5-1 $\mu \mathrm{l}$ DNA template, $0.25 \mu \mathrm{M}$ each primer, $0.2 \mathrm{mM}$ each dNTP, $0.8 \mu \mathrm{l}$ 10X BSA, $0.8 \mu \mathrm{l}$ 10X PCR buffer (Roche), $1.5 \mathrm{mM} \mathrm{MgCl}_{2}$ and $0.4 \mathrm{U}$ of Taq DNA polymerase (Roche). The thermal cycler consisted of $94^{\circ} \mathrm{C}$ for $2 \mathrm{~min}$, followed by 30 cycles of $94^{\circ} \mathrm{C}$ for $40 \mathrm{~s}, 51-60^{\circ} \mathrm{C}$ for $40 \mathrm{~s}$, and $72^{\circ} \mathrm{C}$ for $40 \mathrm{~s}$, and ending with a final extension at $72^{\circ} \mathrm{C}$ for $10 \mathrm{mins}$. Locus-specific annealing temperatures are shown Additional file 1: Table S1). PCR products were sized by capillary electrophoresis on an ABI 3730 sequencer (Applied Biosystems, Inc.), and alleles were scored manually using program GENEMAPPER Ver. 4.0 
software (Applied Biosystems, Inc.). Positive and negative controls as well as three replicate samples were run on each PCR plate for each locus. Repeat genotypes showed high repeatability.

We tested for linkage disequilibrium and deviations from Hardy-Weinberg equilibrium (HWE) in each locus, across populations and overall with an exact test using (10000 permutations; [57]. Significant heterozygote deficiencies were used to identify the presence of null alleles as well as using the program FreeNA [58] to detect the frequencies of null alleles in our dataset. Bonferroni corrections for multiple tests were applied to p-values [59]. To examine population structure, we applied the Bayesian approach implemented in the software Structure 2.3.3 [60] to identify clusters of randomly mating individuals with minimum $\mathrm{HW}$ deviations and linkage disequilibrium. We ran the admixture model with correlated allele frequencies with five replicates of $10^{6}$ Markov Chain Monte Carlo (MCMC) iterations after a burnin of $10^{5}$ from $\mathrm{K}$ (number of parental populations) $=1$ to $\mathrm{K}=10$. To provide the most accurate estimation of $\mathrm{K}$, we used the statistic $\Delta K$ introduced by Evanno et al. [61]. We averaged coefficients of membership across the five replicates using the software CLUMMP 1.1 [62] and DISTRUCT 1.1 [63] was used to plot the graphical representation of this membership. To further examine genetic structure we used the program Arelquin [53] to calculate pair-wise $\mathrm{F}_{\mathrm{ST}}$ values. To visualize the genetic distance, we generated a neighbor-joining tree using the pairwise $\mathrm{F}_{\mathrm{ST}}$ distances in the program MEGA version 4 [51].

\section{Divergence dynamics}

To infer the divergence history between $T$. alpinus and $T$. minimus, we used the coalescent-based isolationwith-migration (IM) model [64] implemented in the program IMa2 [65]. We estimated the following parameters: effective population size of $T$. alpinus $\left(\mathrm{N}_{\mathrm{eALP}}\right), T$. minimus $\left(\mathrm{N}_{\mathrm{eMIN}}\right)$ and their common ancestor $\left(\mathrm{N}_{\mathrm{eA}}\right)$, the migration rate from $T$. alpinus into T.minimus $\left(\mathrm{m}_{\mathrm{ALP}->\mathrm{MIN}}\right)$ and from T. minimus to T. alpinus $\left(\mathrm{m}_{\mathrm{MIN}>\mathrm{ALP}}\right)$, and finally time since divergence (t). IMa2 first uses a Bayesian Markov Chain Monte Carlo (MCMC) approach to integrate over the space of possible genealogies and divergence times then uses the genealogies to estimate the posterior distribution of effective population sizes and migration rates to calculate joint posterior probability of all model parameters [65-67]. We used 10 loci (cyt $b$ sequences, and 9 microsatellite loci: EuAmMS26, EuAmMS41 EuAmMS86, EuAmMS94, EuAmMS37, ACA101, ACA108, ACC2, ACD115) partitioned by species in this analysis. Five microsatellite loci used in the population genetic analyses have complex repeat motifs and therefore may not follow a strict step-wise mutation model. We sub-sampled the entire dataset to improve computational efficiency. Thirty individuals from the microsatellite dataset and twenty individuals from the sequence dataset were randomly chosen from each species for the analysis, with assurance that each geographic area was represented. We used a two-population model where each species was considered a "population". A series of preliminary runs were used to estimate upper bounds on priors and assess mixing. Our final run consisted of 60 chains (geometric heating scheme set $h_{a}=0.980, h_{b}=0.50$ ), a burnin of $3 \times 10^{5}$ steps followed by $30 \times 10^{6}$ steps sampling trees from each locus every 300 steps (ESS > 50). We did two replicates of the final run starting with a different random number seed. Each run took approximately 72 days to finish and both returned parameter estimates that were near identical. Two hundred thousand saved genealogies $(100,000$ from each run) were used to calculate the joint posterior probability of the parameters in L-mode of IMa2. We used a general mammalian nucleotide substitution rate weighted across sites of $8.2 \times 10^{-9}$ [31]; see also [68]) to calculate the locus-wide mutation rate for the $801 \mathrm{bp}$ segment of cyt $b$ to be approximately $6.6 \times 10^{-6}$, and the average mutation rate for the microsatellites as $1.0 \times$ $10^{-4}[69]$. These mutation rates were used to convert the parameter estimates into demographic units (i.e., time in years, population size in individuals and migration rates as individuals/generation). Finally, nested models were tested to determine if the full model fit the data significantly better than models when population sizes and/or migration rates were set to equal or zero.

\section{Results}

\section{Morphological data}

Individuals identified either as T. alpinus or T. minimus are strongly separable by bacular, external, or craniodentalmandibular characters in the multivariate canonical variates analyses of each character set (Figure 2, Additional file 4 on morphological analyses Table S3, Figure S1, S2 \& S3). A few individuals of both species display intermediate posterior probabilities of group membership in external and craniodental-mandibular characters, but the number is minimal $(<2 \%$ for crandiodental-mandibular characters) and not unexpected given the large number of comparisons. Importantly, there is no bias in the distribution of misclassified individuals to the geographically adjacent samples of each species (i.e., misclassified alpinus individuals from the T.alp- $\mathrm{N}$ sample are not placed in the adjacent, but non-overlapping $\mathrm{T}$. min-N sample), which would be expected if there had been, or was continuing interbreeding.

\section{Mitochondrial sequence data}

Our dataset consisted of 246 sequences with 81 variable sites, 40 singleton sites and 47 haplotypes. We found 28 


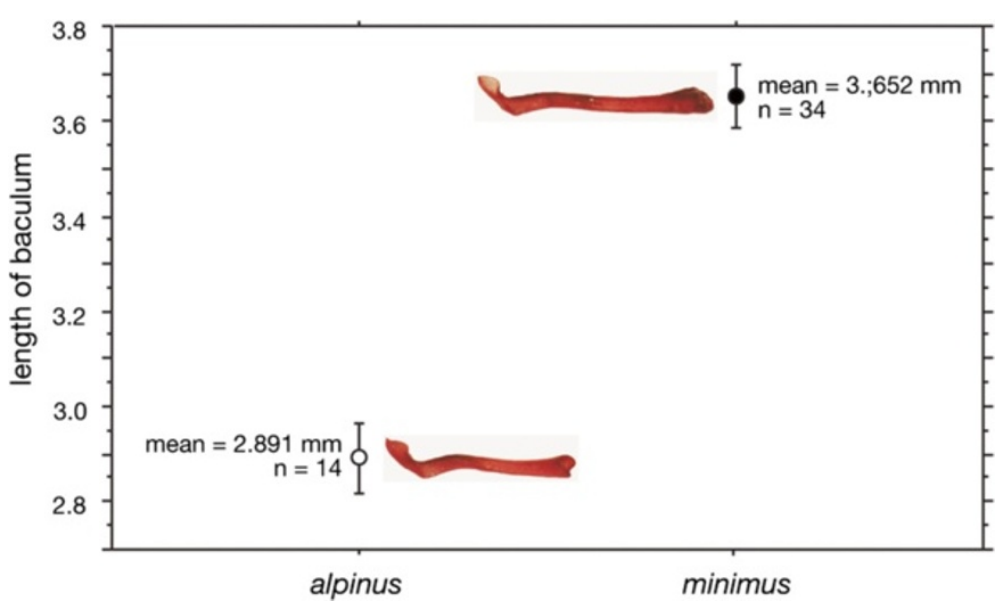

Figure 2 Mean length and standard error of baculum in specimens of T. alpinus and T. minimus in Sierra Nevada, CA. Photograph of baculum of each species shown at right of data point.

haplotypes appear in T. alpinus, 23 haplotypes appear in T. minimus dataset and four shared between species (Table 1). All individual identification numbers, their locality information, and haplotype are provided in Additional file 2: Table S4. Sequences are available on GenBank (GenBank: KJ452863-KJ453106).

There were four haplotypes that were shared by both species. Three shared haplotypes occurred between the T.alp-N and T.min-N sampling localities and one was shared between T.alp-S, T.min-Wht/Inyo and T. min-C groups (Figure 3). The first shared haplotype (AlpMin1) was the second most frequent haplotype present in T. alpinus (29\% of all individuals) where it was confined to individuals from the Yosemite area (T.alp-N) and two from the northern sampling area of T. minimus (T. minN; Figure 3; Additional file 5: Figure S4). AlpMin1 was the most frequent haplotype found in a northern haplogroup we named "North1". The next shared haplotype (AlpMin2) was the most frequent haplotype found in T. minimus (24\%) and detected in only one $T$. alpinus individual from Bullfrog Lake (T. alp-S). All T. minimus individuals with the AlpMin2 haplotype were from the White Mountains, the Inyo Mountains or the central part of our sampling area (Figure 3; T. min-Wht/Iny \& T.min-C). Interestingly, this was the only haplotype that was shared between southern T. alpinus individuals and any of the T. minimus groups. The third shared haplotype (AlpMin3) was in low frequency (6\%) and only found at one site in Yosemite National Park in T. alpinus (Vogelsang Lake, T. alp-N) and in one T. minimus sampled nearby at Bohler Creek (T. min-N). The fourth and last shared haplotype (AlpMin4) was also in low frequency in both species ( $T$. alpinus: $1.4 \%$; $T$. minimus: $2.8 \%$ ) from the northern part of our sampling area. The geographic pattern of shared haplotypes is consistent with historical hybridization events in both the northern and southern portion of T.alpinus' range.

The statistical parsimony haplotype network for $T$. alpinus and T. minimus had a 95\% parsimony limit of 12 steps (Figure 3a). The mtDNA phylogenetic tree

Table 1 Sample size, number of haplotypes detected, haplotype diversity $\left(h_{d}\right)$ nucleotide diversity $\left(\theta_{\pi}, \theta_{s}\right)$ and tests of population expansion/contraction (Tajima's D, Fu' Fs statistics) in T. minimus and T. alpinus, and geographic groups of each species (Figure 1) at the mitochondrial gene, cyt b

\begin{tabular}{|c|c|c|c|c|c|c|c|}
\hline Species & $\mathrm{N}$ & No. of haplotypes & $h_{d}$ & $\theta_{\pi}$ & $\theta_{\mathrm{s}}$ & Tajima's D & Fu's Fs \\
\hline T. alpinus & 139 & 28 & 0.797 & 0.014 & 0.021 & -1.581 & 0.094 \\
\hline T. minimus & 107 & 23 & 0.891 & 0.016 & 0.012 & 0.932 & 1.624 \\
\hline \multicolumn{8}{|c|}{ Geographic groups } \\
\hline T. alp-N & 113 & 12 & 0.695 & 0.012 & 0.008 & 0.9191 & 7.317 \\
\hline T. alp-S & 26 & 17 & 0.951 & 0.026 & 0.038 & -1.492 & -0.489 \\
\hline T. min- $N$ & 40 & 11 & 0.863 & 0.012 & 0.010 & 1.015 & 3.186 \\
\hline T. min- $C$ & 11 & 4 & 0.764 & 0.002 & 0.002 & 0.433 & 0.164 \\
\hline T. min- Wht/Iny & 26 & 6 & 0.517 & 0.008 & 0.008 & 0.0976 & 4.225 \\
\hline T. min-S & 30 & 6 & 0.655 & 0.001 & 0.002 & -1.309 & -1.697 \\
\hline
\end{tabular}




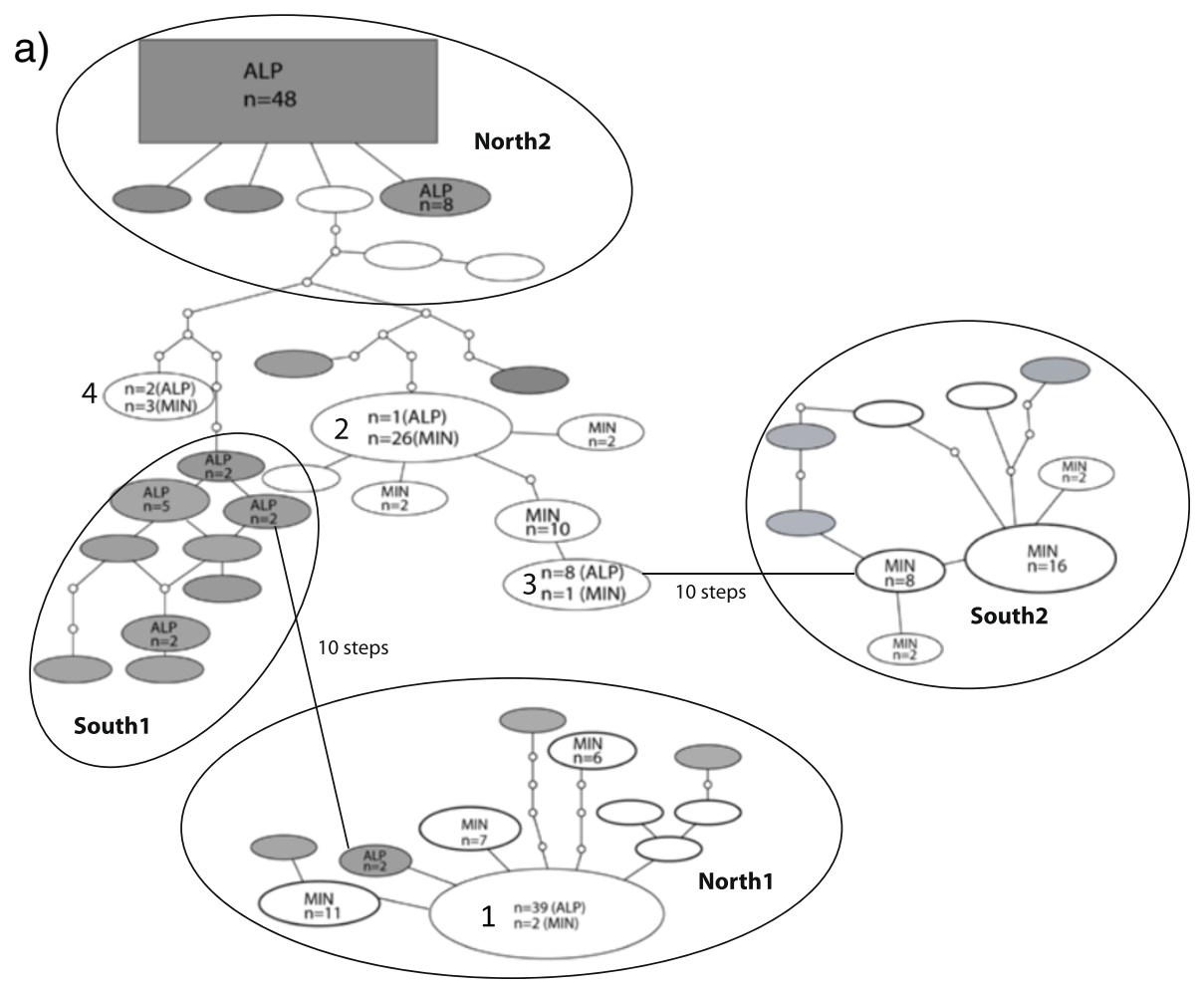

b)

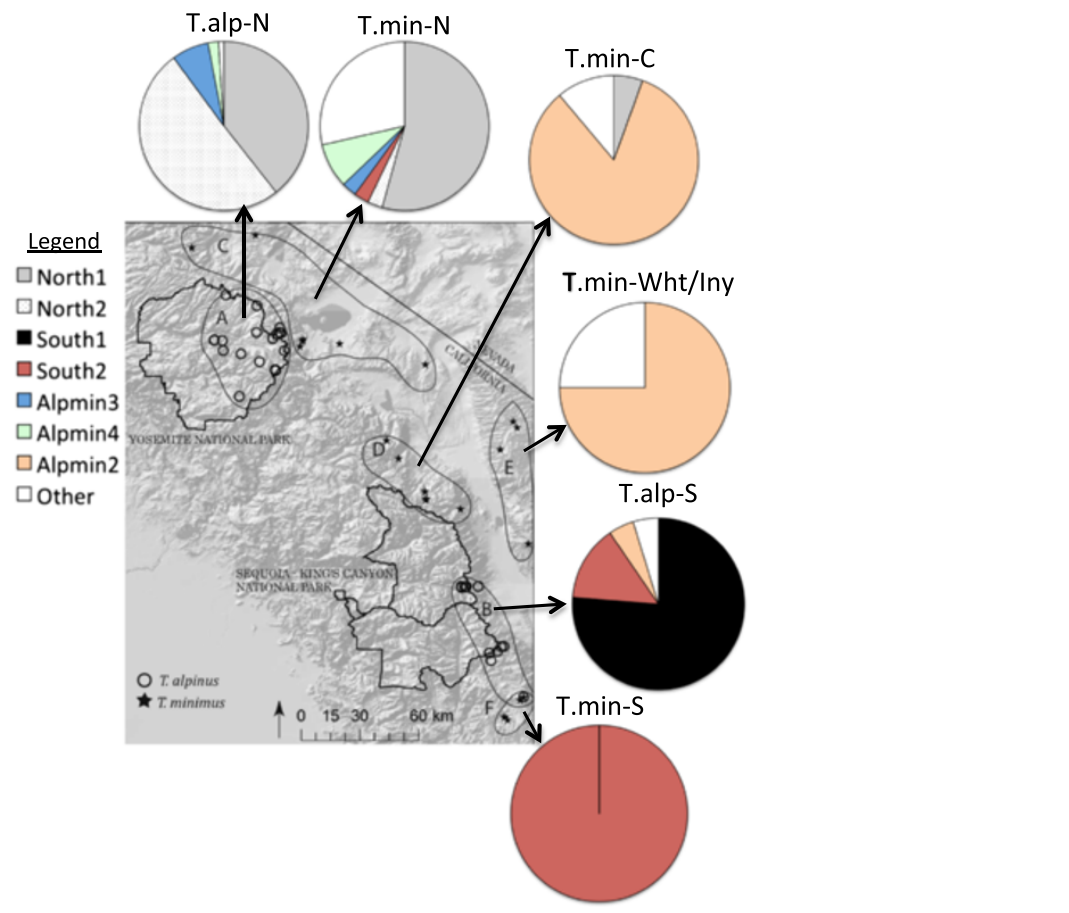

Figure 3 Haplotype network and map of major haplogroups. a) 95\% Statistical parsimony haplotype network for cyt b. Haplotypes are indicated as ovals and scaled by frequency (also noted within oval unless haplotype is unique). Gray represents T. alpinus haplotypes, white represents T. minimus haplotypes and numbered shapes represent shared haplotypes 1) AlpMin1, 2) AlpMin2, 3) AlpMin3, and 4) AlpMin4. Large ovals show groups of individuals with similar haplotypes ("haplogroups") from the same geographic region. There are two distinct northern haplogroups (North1 and North2) and two distinct southern haplogroups (South1 and South2). If haplotypes are not encompassed within an oval, no geographic pattern exists (i.e, found throughout sampling area); b) Pie charts showing the percentage of individuals from each geographic sampling group belonging to the major haplogroups and shared haplotypes (Alpmin 2, 3, \& 4; note that Alpmin1 is within Haplogroup North1). 
estimated by the Bayesian analysis was weakly resolved but supports the network analysis and demonstrates a lack of clear genealogical separation between the two species (Additional file 5: Figure S4). There are four groups of haplotypes that are separated by at least 5 base pair changes and show some geographic structure (Haplogroups North1, North2, South1 and South2, Figure $3 \mathrm{~b}$ ) and three out of four of these contain individuals of both species (North1, North2 and South2). South1 is made up of only T. alpinus individuals from the southern portion of their range. A map of the haplogroups and shared haplotypes shows that genetic similarity is more defined by geography than by species identity (Figure 3b). Two southern T. alpinus haplotypes were more than 12 steps away from the others in the network and are not shown in Figure 3.

The average and the net number of nucleotide substitutions per site were lower between species (Dxy $=0.018$, $\mathrm{Da}=0.003)$ than between the northern and southern T. alpinus populations $(\mathrm{Dxy}=0.021, \mathrm{Da}=0.005)$. The northern $T$. alpinus population was most similar to the northern $T$. minimus population ( $\mathrm{Dxy}=0.015, \mathrm{Da}=0.003$, Table 2; Additional file 6: Figure S5). The southern $T$. minimus samples are the most genetically distinct group sampled, being most different from the northern $T$. minimus population (Dxy $=0.024, \mathrm{Da}=0.017$; Table 2, Additional file 6: Figure S5). There were no significant signals of population expansion or decline (or deviations from neutrality) in either species or geographic populations of species according to Tajima's D or Fu's $F_{s}$ statistics in any of the groups tested (Table 1).

Consistent with the above, the AMOVA attributed $28.63 \%$ of the genetic variation across haplotypes to be between species $\left(\phi_{\mathrm{CT}}=0.28, \mathrm{p}=0.34\right), 37.6 \%$ to be among populations within species $\left(\phi_{\mathrm{SC}}=0.52, \mathrm{p}<0.001\right)$ and $33.8 \%$ of the variation to differences within species $\left(\phi_{\mathrm{ST}}=0.66, \mathrm{p}<0.0001\right)$. By comparison, the AMOVA for the analysis of nuclear loci (see next section) attributed $62 \%$ to variation among groups $\left(\phi_{\mathrm{CT}}=0.62, \mathrm{p}=0.14\right), 5.1 \%$ among populations within groups $\left(\phi_{\mathrm{SC}}=0.13, \mathrm{p}<0.001\right)$ and $32.9 \%$ to variation within populations $\left(\phi_{\mathrm{ST}}=0.67\right.$, $\mathrm{p}<0.001)$. The AMOVA analyses reveal that mtDNA variation is not explained by differences among species or geographic groups, but rather differences within species and populations.

\section{Microsatellite data}

Deviations from $\mathrm{H}-\mathrm{W}$ equilibrium were observed across all loci within species however this is not unexpected given the observed genetic substructure. Within geographic groups, there were deviations from HWE in the T. alpinus $\mathrm{N}$ group but again, there is known substructure in this group [70] so deviations from HWE are expected. A high frequency null allele was detected at the D107 locus in the T. alpinus. We ran the STRUCTURE analysis with and without this locus and the results did not change, therefore, we chose to run the analysis with all 14 loci. No significant linkage disequilibrium was detected after Bonferonni correction. Genetic diversity was highest in the $\mathrm{T}$. min- $\mathrm{N}$ group $\left(A=7.6 ; \mathrm{H}_{\mathrm{e}}=\right.$ $0.84)$, followed by $\mathrm{T}$. min -Wht/Iny $\left(A=6.8 ; \mathrm{H}_{\mathrm{e}}=0.84\right.$; Table 3). The northern $T$. alpinus samples had the lowest genetic diversity of all sampled groups $(A=4.7$, $\mathrm{H}=0.63$ ). Microsatellite genotype data is available in Additional file 7.

\section{Population structure}

The estimated number of parental populations for the microsatellite dataset using the Evanno method was $K=2$, however the mean likelihood values were higher at $\mathrm{K}=5$ and above. The results of the cluster analyses at $\mathrm{K}=2$ separated individuals into two groups by species, with admixture in the T. alp-S (Figure 4a). However, the pairwise $\mathrm{F}_{\mathrm{ST}}$ values between T.alp-S and T.alp-N, and T.alp-S and all of the T. minimus sampling localities show significant genetic differentiation (e.g., pairwise $\mathrm{F}_{\mathrm{ST}}=0.116$ between T.alp-N \& T.alp-S and 0.092 between T.min-N \& T.alp-S, $\mathrm{p}<0.005$, see Table 2), suggesting that hybridization is not ongoing. There was a higher mean likelihood value at $\mathrm{K}=5$ and above, than at $\mathrm{K}=2$, also indicating that $\mathrm{K}=5$ more likely exhibits the genetic structure of these two species across our study area (Additional file 8; Figure $4 \mathrm{~b}$ ). The individual membership graph for $\mathrm{K}=5$ shows further geographic subdivision within $T$. minimus (Figure $4 \mathrm{~b}$ ),

Table 2 Pairwise comparisons of Tamias populations

\begin{tabular}{lcccccc}
\hline & T. alp-N & T. alp-S & T. min-N & T. min-C & T. min-Wht/lny & T. min-S \\
\hline T. alp-N & - & 0.020 & 0.015 & 0.017 & 0.016 & 0.023 \\
T. alp-S & $\mathbf{0 . 1 1 6}$ & - & 0.022 & 0.020 & 0.021 & 0.024 \\
T. min-N & $\mathbf{0 . 1 6 7}$ & $\mathbf{0 . 0 9 2}$ & - & 0.017 & 0.024 \\
T. min-C & $\mathbf{0 . 1 6 6}$ & $\mathbf{0 . 1 0 3}$ & $\mathbf{0 . 0 1 8}$ & - & 0.005 & 0.019 \\
T. min-Wht/Iny & $\mathbf{0 . 1 6 7}$ & $\mathbf{0 . 1 1 4}$ & $\mathbf{0 . 0 2 8}$ & $\mathbf{0 . 0 4 2}$ & $\mathbf{0 . 1 4 7}$ \\
T. min-S & $\mathbf{0 . 2 2 7}$ & $\mathbf{0 . 1 6 8}$ & $\mathbf{0 . 1 1 8}$ & $\mathbf{0 . 1 2 4}$ & 0.020 \\
\hline
\end{tabular}

Statistically significant Fst values shown in bold font $(P<0.005,10000$ permutations).

Pairwise Dxy values from the mtDNA data are given above the diagonal and pairwise Fst-values from the microsatellite data below the diagonal. 
Table 3 Sample size (N), average allelic richness ( $A$; corrected for differences in sample size), observed and expected heterozygosity $\left(\mathrm{H}_{\mathrm{o}}, \mathrm{H}_{\mathrm{e}}\right.$ \& standard deviation (sd)) in $T$. alpinus and T. minimus at 14 microsatellite loci

\begin{tabular}{lccccc}
\hline Species & Locality & $\mathbf{N}$ & $\boldsymbol{A}$ & $\mathbf{H}_{\mathbf{o}}(\mathbf{s d})$ & $\mathbf{H}_{\mathbf{e}}(\mathbf{s d})$ \\
\hline T. alpinus & North (YNP) & 149 & 4.7 & $0.57(0.19)$ & $0.63(0.21)$ \\
& South & 17 & 6.0 & $0.71(0.19)$ & $0.75(0.17)$ \\
T. minimus & North & 57 & 7.6 & $0.73(0.14)$ & $0.84(0.07)$ \\
& White/inyo mtns & 33 & 6.8 & $0.71(0.18)$ & $0.82(0.09$ \\
& Central & 42 & 6.4 & $0.62(0.12)$ & $0.78(0.10)$ \\
& South & 29 & 5.1 & $0.58(0.23)$ & $0.68(10.18)$ \\
\hline
\end{tabular}

with T.alp-S highly differentiated from T.alp-N. Based on cluster membership percentages, T. min-N \& T.min-C is one genetic cluster showing evidence of gene flow with T.min-Wht/Iny, while T.min-S is well differentiated. (Additional file 8, Figure 4a \& b). K values above five did not greatly improve likelihood scores but do reveal subdivision between T.min-N \& T.min-C and within T.alp-N (graphs not shown). The T.alp-S sample appears as a distinct cluster, with one exception. There is one T. alpinus individual from Bullfrog Lake (MVZ224480) in the T.alp-S geographic group that was assigned to T.Min-N based on its genotype at 14 loci (Figure 4b). This individual had a divergent mtDNA haplotype shown with arrow on Bayesian tree (location shown with green triangle on the map of Additional file 5: Figure S4) and morphologically is unambiguously identified as a T. alpinus.

The pairwise $\mathrm{F}_{\mathrm{ST}}$ values between clusters showed significant differentiation across all clusters and ranged from 0.018 between T.min- $\mathrm{N}$ and T.min-C to 0.227 between T.alp-N and T.min-S (Table 2). In contrast to the results for mtDNA, the neighbor-joining tree based on $\mathrm{F}_{\mathrm{ST}}$ shows that groups of the same species are genetically more similar to each other than to the other species (Additional file 8: Figure S7) although the southern populations of both species (T. alp-S and T.min-S) are both differentiated from their more northern conspecifics.

\section{Coalescent analysis of divergence history}

Using IMa2, we estimated the following parameters: effective population size of $T$. alpinus $\left(\mathrm{Ne}_{\mathrm{ALP}}\right), T$. minimus
$\left(\mathrm{Ne}_{\mathrm{MIN}}\right)$ and the common ancestor $\left(\mathrm{Ne}_{\mathrm{A}}\right)$ the migration rate from $T$. alpinus into T.minimus $\left(\mathrm{m}_{\mathrm{ALP}->\mathrm{MIN}}\right)$ and from $T$. minimus to $T$. alpinus ( $\mathrm{m}_{\mathrm{MIN}->\mathrm{ALP}}$ ) and time since divergence ( $\mathrm{t}$ ) (Table 4). The split between T. alpinus and T. minimus lineages was estimated by IMa2 to have occurred in the mid-Pleistocene, at approximately $450 \mathrm{ka}$. There is a sharp peak in the posterior density plot at this value however, the plot plateaus at a low, but non- zero value for higher values of $t$, including when a higher upper bound on the divergence time prior is used (results not shown). The mean effective population size $\left(\mathrm{N}_{\mathrm{e}}\right)$ of $T$. alpinus was estimated to be much smaller than $T$. minimus with non-overlapping confidence intervals ( $\mathrm{T}$. alp mean $\mathrm{N}_{\mathrm{e}}=430,625$. 95\% HPD 230,019- 648,519; T. min mean $\mathrm{N}_{\mathrm{e}}=1,448,317,95 \%$ HPD 833,365-2,095,096). The size of the daughter populations is small compared to the ancestral population $\left(\mathrm{N}_{\mathrm{eA}}=6,680,761\right)$. Migration estimates between the two species showed strong evidence for unidirectional migration from $T$. minimus into $T$. alpinus $\left(2 N_{\mathrm{m}}=0.5441, \mathrm{p}<0.001\right)$. Migration from $T$. alpinus into $T$. minimus $(2 \mathrm{Nm}=0.002)$ was not significantly different from zero (Table 4; Figure 5). Testing of 24 nested models using the Likelihood Ratio Test (LRT) rejected models with zero migration rates and the nested model with the strongest support allowed migration from $T$. minimus into T. alpinus but zero migration in the other direction. This nested model had the same log-likelihood as the full model, and had the highest log likelihood out of all 24 models tested, providing strong support that the unidirectional migration model is a good description of the data.

\section{Discussion}

We examined the evolutionary relationship of $T$. alpinus and $T$. minimus using cytochrome $\mathrm{b}$ and microsatellites to help elucidate the divergence history of $T$. alpinus in the Sierra Nevada. Microsatellite analyses were used to provide a contemporary view of this relationship and to examine details of population genetic structure within and across species. We found that T. alpinus and $T$. minimus populations share mitochondrial haplotypes with no overall geneaological separation, and that diversity at this locus is better explained by geography than by species' boundaries. This pattern indicates either recent speciation of $T$. alpinus from $T$. minimus with

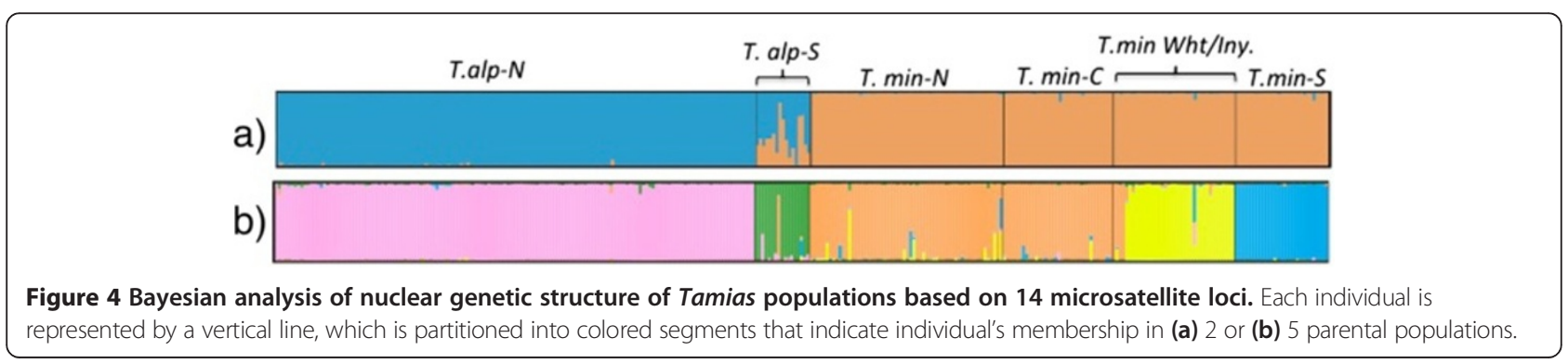


Table 4 Parameter estimates from IMa2 runs for $T$. alpinus and $T$. minimus

\begin{tabular}{llllll}
\hline & $\mathbf{N}_{\mathbf{e}}$ & $\mathbf{N}_{\mathrm{eA}}$ & $\mathbf{t}$ & $\mathbf{2 N}_{\mathbf{m}}$ T.min to T. alp & $\mathbf{2 N}_{\mathbf{m}}$ T.alp to T.min \\
\hline T. alpinus & 430625 & 6680761 & 446538 & $\mathbf{0 . 5 4 4 1}$ & 0.002 \\
HPD95 low-high & $230019-648513$ & $778846-18058846^{*}$ & $115-^{*}$ & $0.1986-0.9981^{*}$ & $0-0.9463^{*}$ \\
T. minimus & 1448317 & & & & \\
HPD95 low-high & $833365-2095096$ & & & & \\
\hline
\end{tabular}

*HPD may not be useful because posterior density does not reach low levels near upper $\left(\mathrm{N}_{\mathrm{eA}}, \mathrm{t}\right)$ or lower $(2 \mathrm{Nm})$ limit of prior. In the case of $\mathrm{N}_{\mathrm{eA}} \& \mathrm{t}$, even with higher values set for the prior, the posterior density plot plateaus at low but nonzero values (see Figure 5).

Bold font shows significance of $p<0.001$.

$\mathrm{N}_{\mathrm{e}}$ estimates are mean values and migration rate parameters are the HiPt of the posterior probability.

retention of ancestral polymorphism, or extensive introgression subsequent to splitting. In contrast to the mtDNA sequence data, the analyses of nuclear microsatellite loci and morphology revealed that the two species are genetically distinct. Although there are highly differentiated populations within species, populations of the same species are more similar to each other than they are to members of the other species. This suggests that contemporary hybridization is not widespread along the geographic boundary between $T$. minimus and $T$. alpinus. Coalescent analysis of divergence history revealed mid to late Pleistocene divergence and low, but significant gene flow between the two lineages. Overall, our study suggests that: speciation between T. alpinus and T. minimus is relatively recent, secondary contact and historical introgression has occurred, and there is little evidence or opportunity for contemporary hybridization given the current distribution of these two species.
Differentiating between the genetic signature of incomplete lineage sorting and historical hybridization is difficult; however, distinguishing between the two is important in addressing non-concordance among characters in closely related species [71]. The spatial pattern of genetic variation across species can help to provide an objective assessment of which process is more likely to have occurred because each should produce a specific spatial pattern [30,72]. The results of our mitochondrial sequences show no strong spatial structure within species. Both the Bayesian tree and haplotype network indicate the two species are completely intermingled across the landscape. Recent hybridization should show a clustered pattern, where introgressed alleles are more common at or near the contact zone of the two species; in contrast, ancestral polymorphism should be diffuse and uniform across space [30]. However, the spatial patterns described above assume a contact zone between species,
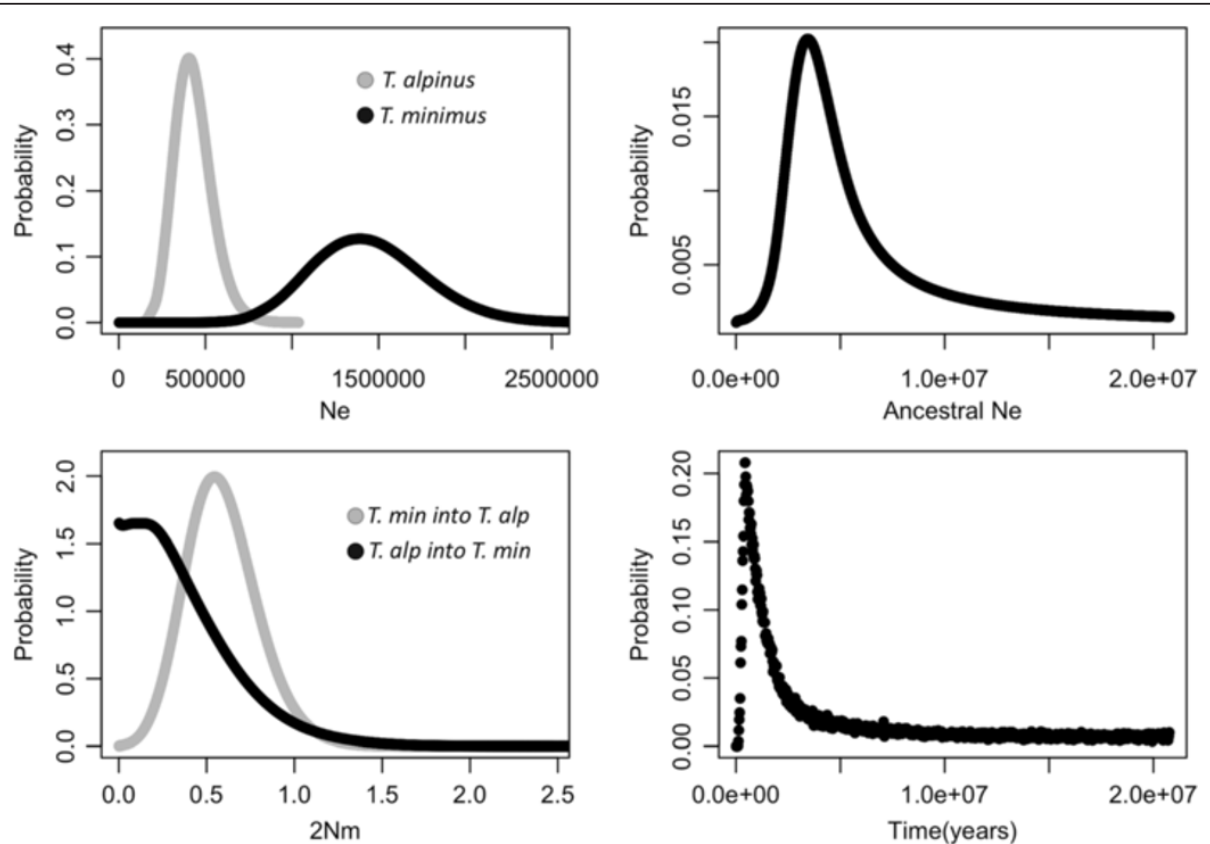

Figure 5 Posterior density plots of parameters from Isolation with Migration (IMa2) analysis. Top left: effective population size of T. alpinus and T. minimus; top right: ancestral effective population size; bottom left: effective number of migration events per generation between T. alpinus and T. minimus; bottom right: divergence time between T. alpinus and T. minimus. 
and for this study, we were unable to obtain samples of both species from the same location. The one site where they were collected in close proximity in 1911 (Little Brush Meadow, Tulare Co., CA) showed distinct and divergent haplotypes between species. The single $T$. minimus taken from this locality had a unique haplotype that clustered with the southern minimus haplogroup in the network (South2 Figure 3, Additional file 5: Figure S4) whereas the $T$. alpinus from that location and three other $T$. alpinus from the general area collected at the same time, all clustered within southern T. alpinus haplogroup (South1). Overall, the distribution of shared haplotypes reflects geographic proximity, not current contact; northern T. alpinus and T. minmus shared three haplotypes and southern T. alpinus and central and southern T. minimus shared one. This geographic pattern, along with the results of the IMa2 analysis suggest that hybridization occurred at some point in the past but given the results of the microsatellite analysis and current distribution of the two species, hybridization is not currently ongoing.

There were potential problems with the parameter estimates using IMa2, in particular, that for divergence time. The first is that our microsatellite data exhibit genetic structure within lineages (recall that in this analysis, each species was considered a "population"), which may lead to an overestimation of divergence time [73]. Second, the right tail of the posterior density plot reached low but non-zero values potentially making the $95 \%$ HPD high and low estimates unreliable (i.e. posterior density distribution did not converge within prior range). Given these caveats, the estimate of divergence time between $T$. alpinus and T. minimus from IMa2 is about $450 \mathrm{ka}$ with some support of it being as recent as $110 \mathrm{ka}$ (the lower 95\% HPD of $\mathrm{t}$ ). This timeframe occurs in the mid to late Pleistocene, a time of extreme climate fluctuations in the Sierra Nevada including several major glaciations with prolonged glacial rather than interglacial periods [9]. The coalescent analysis also supports low but significant gene flow subsequent to splitting from $T$. minimus into $T$. alpinus. Given the relatively small population size estimated by the IMa2 analysis for $T$. alpinus compared to T. minimus and considering that T. alpinus is a range restricted endemic, it is conceivable that the T. alpinus population would receive more genes from $T$. minimus than the other way around.

The Pleistocene shaped the genetic structure and distributions of many species (reviewed in [7]) and its role in the speciation in several North American taxa, though sometimes debated, is clear (e.g., [74-76]). It is plausible that a founding population of $T$. alpinus became isolated in a refugium from an adjacent $T$. minimus population. A recent study that used sequence data from reproductive protein genes showed that $T$. alpinus, characterized by strongly divergent sequences, is a monophyletic group nested within T. minimus species complex [32]. This nested pattern is consistent with expectations for a peripheral isolate of a widespread species providing further support to our results suggesting that speciation of T. alpinus is recent. The IMa2 analysis also supports this notion with a parameter estimate for the effective population size of $T$. alpinus $\left(\mathrm{N}_{\mathrm{eALP}}=430,625\right)$, substantially smaller than the estimate of the effective population size of $T$. minimus $\left(\mathrm{N}_{\mathrm{eMIN}}=1,448,317\right)$. Finally, although the estimates of migration between species were low (95\% HPD high $<1$ from $T$. minimus to $T$. alpinus), there is significant evidence of historical genetic introgression between species, adding to the complexity of the divergence dynamics between these two species. The results of this study adds to the growing number of studies that have highlighted the importance of glacial-interglacial refugia in recently derived species across taxa in the central and southern Sierra Nevada (e.g., [12,14]).

Hybridization can play an important role in the evolution of species [77-79]. It was previously accepted that the morphological differences in bacular morphology in western chipmunks mechanically prevented hybridization between species and was considered a strong premating barrier to gene flow $[43,80]$. However, several recent studies have documented both historical and ongoing hybridization in two non-sister species of Tamias and suggest that it may be more common in the genus than previously thought $[30,31,42]$. Our analyses provide little or no evidence for current introgression across the species boundaries; however, the potential for contemporary gene flow between these species where they come into close proximity in the southern portion of their range exists. One apparent hybrid individual, morphologically determined to be a $T$. alpinus with a divergent $T$. alpinus haplotype, was more similar to $T$. minimus than T. alpinus based on 14 microsatellite loci. The assignment of this individual to the T.min-N population is puzzling because the two localities are far apart geographically (at least $80 \mathrm{~km}$ ). Despite extensive survey effort along the eastern flank of the Sierra Nevada, we have not found a locality of co-occurrence where there is direct potential for hybrid matings. Furthermore, our morphological analyses show no evidence of hybridization and species were easily discriminated based on the measured morphological characters.

\section{Conclusions}

Speciation is a prolonged process that likely has phases in different spatial contexts $[81,82]$. Here, we provided evidence of recent speciation with limited yet significant post-divergence gene flow between the Alpine chipmunk and its closest relative. Our approach revealed an interesting and complex pattern of shared and intermingled 
haplotypes across species and highly differentiated populations within. The presence of geographic structure of shared haplotypes between these closely related lineages could be a result of allopatric speciation with secondary contact, but the same pattern could be a result of zones of primary parapatric speciation. As theory suggests, any mechanism that can cause divergence in allopatry can also occur in parapatry, as long as the selective gradient acting on differentiation is strong enough to counterbalance continuous gene flow [83]. In order to further examine the genetic patterns that emerged in this study, future work comparing genome-level patterns of diversity between these two species may reveal regions of the genome under strong divergent selection; a pattern not expected in an allopatric speciation scenario [84]. Additionally, environmental niche models (ENMs) used to predict historical ranges aid in the identification of areas of isolation and the potential for secondary contact in the past. The environmental modeling results can be combined with genetic data to test alternative hypotheses of allopatric speciation with secondary contact or primary parapatric speciation (e.g. [85]). A multifaceted approach including building historical ENMs and genomic data combined with increased sampling could further improve our understanding of the evolutionary history of Alpine chipmunk, a species that appears to be under threat due to recent climate change [70,86]. A clear understanding of this species evolutionary history could help us understand its vulnerability in the face of environmental change.

\section{Additional files}

Additional file 1: Table S1. Summary of species-specific differences between T. alpinus and T. minimus.

Additional file 2: Table S4. ID/Catalogue numbers of all samples sequenced at cytochrome $b$.

Additional file 3: Table S2. Microsatellite and cytochrome $b$ primers used in analyses.

Additional file 4: Detailed results and additional figures for morphological analyses.

Additional file 5: Figure S4. Bayesian estimate $(G T R+I+\Gamma)$ of phylogeny of cyt $b$.

Additional file 6: Figure S5. $N J$ tree of the relationships among geographic groups of T. alpinus and T. minimus based on the average number of nucleotide substitutions per site (Dxy, Nei [51]) at cyt $b$.

Additional file 7: Microsatellite Genotype Data used in STRUCTURE analysis.

Additional file 8: Figure S6. Estimation of the true number of clusters using $\Delta \mathrm{K}$ (Evanno et al [62]) and Figure S7. Unrooted NJ tree of the relationship among populations using $\mathrm{F}_{\mathrm{ST}}$.

\section{Authors' contributions}

EMR and JLP collected the samples, with assistance from members of the Grinnell Resurvey Project field team. EMR carried out the lab work, data analysis and interpretation, and wrote the manuscript. JLP carried out the morphological analyses. JLP and CM provide the resources and context for the study, discussed the design and general methods of analysis and edited the manuscript. EMR, JLP and CM all read and approved the final manuscript.

\section{Acknowledgements}

We are grateful to Chris Conroy, Jessica Castillo, Karen Rowe, Kevin Rowe, Carol Patton, Les Chow and the YNP resurvey team for their role in collecting the field data and Marisa Lim for her assistance in the lab. Sonal Singhal provided valuable advice for implementing the IMa2 analyses. The manuscript was improved through feedback from Sonal Singhal, Sean Rovito, Juan Parra, Margarita Hadjistylli, Pauline Kamath, Kari RoeschGoodman, Justin Brashares and three anonymous reviewers. E. M. Rubidge was supported by a National Science \& Engineering Research Council (NSERC) PGS-D award, the Museum of Vertebrate Zoology, and the Environmental Science, Policy and Management Department at UC Berkeley, during this research. The project was funded by the Museum of Vertebrate Zoology at UC Berkeley, the Yosemite Fund, the National Geographic Society and the National Science Foundation.

\section{Author details}

${ }^{1}$ Museum of Vertebrate Zoology, 3101 Valley Life Sciences Building University of California, Berkeley, California 94720-3160, USA. ${ }^{2}$ Royal British Columbia Museum, 675 Belleville Street, Victoria, British Columbia V8W 9W2, Canada. ${ }^{3}$ Research School of Biology, The Australian National University, Acton, ACT 0200, Australia.

Received: 12 September 2013 Accepted: 11 February 2014 Published: 23 February 2014

\section{References}

1. Dobzhansky T: Genetics and the Origin of Species. 3rd edition. New York: Columbia University Press; 1951.

2. Schluter D: Ecology and the origin of species. Trends Ecol Evol 2001, 16:372-380.

3. Mallet J: Hybrid speciation. Nature 2007, 446:279-283.

4. Pinho C, Hey J: Divergence with gene flow: models and data. Annu Rev Ecol Evol Syst 2010, 41:215-230.

5. Abbott R, Albach D, Ansell S, Arntzen JW, Baird SJE, Bierne N, Boughman JW, Brelsford A, Buerkle CA, Buggs R, Butlin RK, Dieckmann U, Eroukhmanoff F, Grill A, Cahan SH, Hermansen JS, Hewitt G, Hudson AG, Jiggins C, Jones J, Keller B, Marczewski T, Mallet J, Martinez-Rodriguez P, Moest M, Mullen S, Nichols R, Nolte AW, Parisod C, Pfennig K, et al: Hybridization and speciation. J Evol Biol 2013, 26:229-246.

6. Avise JC, Walker D, Johns GC: Speciation durations and Pleistocene effects on vertebrate phylogeography. Proc R SOC B Biol SCi 1998, 265:1707-1712.

7. Hewitt GM: Genetic consequences of climatic oscillations in the Quaternary. Philos Trans R Soc B 2004, 359:183-195.

8. Avise JC: Phylogeography: The History and Formation of Species. Cambridge, Massachusetts: Harvard University Press; 2000.

9. Gillespie AR, Zehfuss PH: Glaciations of the Sierra Nevada, California, USA. In Quaternary Glaciations and Chonology. Volume 2b, Part II: North America, Developments in Quartenary Science. Edited by Ehlers J, Gibbard PL. Amsterdam: Elsevier; 2004.

10. Grayson DK: The Great Basin: a Natural History. Berkeley, CA: University of California Press; 2011.

11. Feldman CR, Spicer GS: Comparative phylogeography of woodland reptiles in California: repeated patterns of cladogenesis and population expansion. Mol Ecol 2006, 15:2201-2222.

12. Schoville SD, Roderick GK: Alpine biogeography of Parnassian butterflies during Quaternary climate cycles in North America. Mol Ecol 2009, 18:3471-3485.

13. Hull JM, Keane JJ, Savage WK, Godwin SA, Shafer JA, Jepsen EP, Gerhardt R, Stermer C, Ernest HB: Range-wide genetic differentiation among North American great gray owls (Strix nebulosa) reveals a distinct lineage restricted to the Sierra Nevada, California. Mol Phylo Evol 2010, $56: 212-221$ 
14. Rovito SM: Lineage divergence and speciation in the Web-toed Salamanders (Plethodontidae: Hydromantes) of the Sierra Nevada, California. Mol Ecol 2010, 19:4554-4571.

15. Poage MA, Chamberlain CP: Stable isotopic evidence for a Pre-Middle Miocene rain shadow in the western Basin and Range: implications for the paleotopography of the Sierra Nevada. Tectonics 2002, 21(4).

16. Mulch A, Sarna-Wojcicki AM, Perkins ME, Chamberlain CP: A Miocene to Pleistocene climate and elevation record of the Sierra Nevada (California). Proc Natl Acad Sci USA 2008, 105:6819-6824.

17. Grayson DK: The Late Quaternary biogeographic histories of some Great Basin mammals (western USA). Quat Sci Rev 2006, 25:2964-2991.

18. Brown JH: Mammals on mountaintops - nonequilibrium insular biogeography. Am Nat 1971, 105:467.

19. Grayson DK: Mammalian responses to Middle Holocene climatic change in the Great Basin of the western United States. J Biogeography 2000, 27:181-192.

20. Rickart EA: Elevational diversity gradients, biogeography and the structure of montane mammal communities in the intermountain region of North America. Global Ecol Biogeography 2001, 10:77-100.

21. Guyton B: Glaciers of California: Modern Glaciers, Ice Age Glaciers, Origin of Yosemite Valley, and a Glacial Tour in Sierra Nevada. Berkeley and Los Angeles: University of California Press; 1998.

22. Matthes F: Report of the committee on glaciers 1939-1940. Trans Am Geophys Union 1940, 518:396-406.

23. Glazner AF, Manley CR, Marron JS, Rojstaczer S: Fire or ice: Anticorrelation of volcanism and glaciation in California over the past 800,000 years. Geophys Res Lett 1999, 26:1759-1762.

24. Basagic HJ, Fountain AG: Quantifying 20th century glacier change in the Sierra Nevada, California. Arct Antarct Alp Res 2011, 43:317-330.

25. Gompert Z, Fordyce JA, Forister ML, Shapiro AM, Nice CC: Homoploid hybrid speciation in an extreme habitat. Science 2006, 314:1923-1925.

26. Schoville SD, Stuckey M, Roderick GK: Pleistocene origin and population history of a neoendemic alpine butterfly. Mol Ecol 2011, 20:1233-1247.

27. Good JM, Sullivan J: Phylogeography of the red-tailed chipmunk (Tamias ruficaudus), a northern Rocky Mountain endemic. Mol Ecol 2001, 10:2683-2695.

28. Piaggio A, Spicer GS: Molecular phylogeny of the chipmunks inferred from mitochondrial cytochrome b and cytochrome oxidase II gene sequences. Mol Phylo Evol 2001, 20:335-350.

29. Demboski JR, Sullivan J: Extensive mtDNA variation within the yellow-pine chipmunk, Tamias amoenus (Rodentia: Sciuridae), and phylogeographic inferences for northwest North America. Mol Phylo Evol 2003, 26:389-408.

30. Good JM, Demboski JR, Nagorsen DW, Sullivan J: Phylogeography and introgressive hybridization: Chipmunks (genus Tamias) in the northern Rocky Mountains. Evolution 2003, 57:1900-1916.

31. Good JM, Hird S, Reid N, Demboski JR, Steppan SJ, Martin-Nims TR, Sullivan J: Ancient hybridization and mitochondrial capture between two species of chipmunks. Mol Ecol 2008, 17:1313-1327.

32. Reid N, Demboski JR, Sullivan J: Phylogeny estimation of the radiation of Western North American Chipmunks (tamias) in the face of introgression using reproductive protein genes. Syst Biol 2012, 61:44-62.

33. Levenson H, Hoffmann RS, Nadler CF, Deutsch L, Freeman SD: Systematics of the Holarctic chipmunks (Tamias). J Mamm 1985, 66:219-242.

34. Hoffmann RS: Different voles for different holes: environmental restrictions on refugial survival of mammals. In Proceedings of the Second International Congress of Systematic and Evolutionary Biology. Vancouver, BC 1981:25-45

35. Hofmann RS, Anderson CG, Thorington RJ, Heaney L: Family Sciurdae. In Mammal Species of the World: A Taxonomic and Geographic Reference. Edited by Wilson DE, Reeder DM. Washington: Smithsonian Institute Press; 1993:419-465.

36. Bergstrom BJ, Hoffmann RS: Distribution and Diagnosis of 3 species of chipmunks (Tamias) on the front range of Colorado. Southwest Nat 1991 36:14-28.

37. Verts BJ, Carraway LN: Tamias minimus. Mamm Species 2001, 653:1-10.

38. Sullivan RM: Phyletic, biogeographic, and ecologic relationships among montane populations of least Chipmunks (eutamias minimus) in the Southwest. Syst Zool 1985, 34:419-448.

39. Johnson DH: Systematic review of the chipmunks (genus Eutamias) of California. Univ Calif Publ Zool 1943, 48:63-143.

40. Sutton DA: Tamias amoenus. Mamm Species 1992, 390:1-8.
41. Grinnell J, Storer TI: Animal Life in Yosemite. Berkeley, CA: University of California Press; 1924.

42. HIRD S, Sullivan J: Assessment of gene flow across a hybrid zone in red-tailed chipmunks (Tamias ruficaudus). Mol Ecol 2009, 18:3097-3109.

43. Patterson BD, Thaeler CSJ: The Mammalian Baculum: hypotheses on the nature of bacular variability. J Mamm 1982, 63:1-15.

44. Mullen LM, Hoekstra HE: Natural selection along an environmental gradient: classic cline in mouse pigmentation. Evolution 2008, 62:1555-1570.

45. Smith MF: Phylogenetic relationships and geographic structure in Pocket Gophers in the Genus Thomomys. Mol Phylo Evol 1998, 9:1-14.

46. Ronquist F, Huelsenbeck JP: MrBayes 3: Bayesian phylogenetic inference under mixed models. Bioinformatics 2003, 19:1572-1574.

47. Posada D: jModelTest: phylogenetic model averaging. Mol Biol Evol 2008 , 25:1253-1256

48. Templeton AR, Crandall KA, Sing CF: A cladistic-analysis of phenotypic associations with haplotypes inferred from restriction endonuclease mapping and DNA sequence data 3. Cladogram estimation. Genetics 1992, 132:619-633

49. Clement M, Posada D, Crandall KA: TCS: a computer program to estimate gene genealogies. Mol Ecol 2000, 9:1657-1659.

50. Nei M: Molecular Evolutionary Genetics. New York, NY: Columbia University Press; 1987.

51. Tamura K, Dudley J, Nei M, Kumar S: MEGA4: molecular evolutionary genetics analysis (MEGA) software version 4.0. Mol Biol Evol 2007, 24:1596-1599.

52. Librado P, Rozas J: DnaSP v5: a software for comprehensive analysis of DNA polymorphism data. Bioinformatics 2009, 25:1451-1452.

53. Excoffier L, Laval G, Schneider S: Arlequin (version 3.0): an integrated software package for population genetics data analysis. Evol Bioinforma 2005, 1:47-50

54. Tajima F: Statistical-method for testing the neutral mutation hypothesis by DNA polymorphism. Genetics 1989, 123:585-595.

55. Fu YX: Statistical tests of neutrality of mutations against population growth, hitchhiking and background selection. Genetics 1997, 147:915-925.

56. Schulte-Hostedde Al, Gibbs HL, Millar JS: Microsatellite DNA loci suitable for parentage analysis in the yellow-pine chipmunk (Tamias amoenus). Mol Ecol 2000, 9:2180-2181

57. Raymond M, Rousset F: An exact test for population differentiation. Evolution 1995, 49:1280-1283.

58. Chapuis MP, Estoup A: Microsatellite null alleles and estimation of population differentiation. Mol Biol Evol 2006, 24:621-631.

59. Rice WR: Analyzing tables of statistical tests. Evolution 1989, 43:223-225.

60. Pritchard JK, Stephens M, Donnelly P: Inference of population structure using multilocus genotype data. Genetics 2000, 155:945-959.

61. Evanno G, Regnaut S, Goudet J: Detecting the number of clusters of individuals using the software structure: a simulation study. $\mathrm{Mol}$ Ecol 2005, 14:2611-2620.

62. Jakobsson M, Rosenberg NA: CLUMPP: a cluster matching and permutation program for dealing with label switching and multimodality in analysis of population structure. Bioinformatics 2007, 23:1801-1806.

63. Rosenberg NA: DISTRUCT: a program for the graphical display of population structure. Mol Ecol Resour 2004, 4:137-138.

64. Nielsen R, Wakeley J: Distinguishing migration from isolation: a Markov chain Monte Carlo approach. Genetics 2001, 158:885-896.

65. Hey J: Isolation with migration models for more than Two populations. Mol Biol Evol 2010, 27:905-920.

66. Hey J, Nielsen R: Multilocus methods for estimating population sizes, migration rates and divergence time, with applications to the divergence of Drosophila pseudoobscura and D-persimilis. Genetics 2004, 167:747-760.

67. Hey J, Nielsen R: Integration within the Felsenstein equation for improved Markov chain Monte Carlo methods in population genetics. Proc Natl Acad Sci USA 2007, 104:2785-2790.

68. Pesole G, Gissi C, de Chirico A, Saccone C: Nucleotide substitution rate of mammalian mitochondrial genomes. J Mol Evol 1999, 48:427-434.

69. Schlötterer C: Evolutionary dynamics of microsatellite DNA. Chromosoma 2000, 109:365-371.

70. Rubidge EM, Patton JL, Lim M, Burton AC, Brashares JS, Moritz C: Climateinduced range contraction drives genetic erosion in an alpine mammal. Nat Clim Chang 2012, 2:285-288.

71. Avise JC, Ball MR Jr: Principles of genealogical concordance in species concepts and biological taxonomy. In Oxford Surveys in Evolutionary 
Biology. Edited by Futuyma D, Antonovics J. New York: Oxford University Press; 1990:45-67.

72. Goodman SJ, Barton NH, Swanson G, Abernethy K, Pemberton JM: Introgression through rare hybridization: a genetic study of a hybrid zone between red and sika deer (genus Cervus) in Argyll, Scotland. Genetics 1999, 152:355-371.

73. Wakeley J: The effects of subdivision on the genetic divergence of populations and species. Evolution 2000, 54:1092-1101.

74. Knowles LL, Otte D: Phylogenetic analysis of montane grasshoppers from western North America (Genus Melanoplus, Acrididae: melanoplinae). Ann Entomol Soc Am 2000, 93:421-431.

75. Knowles LL: Did the Pleistocene glaciations promote divergence? Tests of explicit refugial models in montane grasshopprers. Mol Ecol 2001, 10:691-701.

76. Johnson NK, Cicero C: New mitochondrial DNA data affirm the importance of Pleistocene speciation in North American birds. Evolution 2004, 58:1122-1130

77. Arnold ML: Natural hybridization as an evolutionary process. Ann Rev Ecol Syst 1992, 23:237-261.

78. Seehausen O: Hybridization and adaptive radiation. Trends Ecol Evol 2004, 19:198-207.

79. Rieseberg LH: Hybrid origins of plant species. Ann Rev Ecol Syst 1997, 28:359-389.

80. Adams DR, Sutton DA: A description of bacullum and os clitoris of Eutamias townsendii ochrogenys. J Mamm 1968, 49:764.

81. Butlin RK, Galindo J, Grahame JW: Sympatric, parapatric or allopatric: the most important way to classify speciation? Philos Trans $R \operatorname{Soc} B$ 2008, 363:2997-3007.

82. Butlin R, Debelle A, Kerth C, Snook RR, Beukeboom LW, Cajas RFC, Diao W, Maan ME, Paolucci S, Weissing FJ, van de Zande L, Hoikkala A, Geuverink E, Jennings J, Kankare M, Knott KE, Tyukmaeva VI, Zoumadakis C, Ritchie MG, Barker D, Immonen E, Kirkpatrick M, Noor M, Macias Garcia C, Schmitt T, Schilthuizen M, Network MCS: What do we need to know about speciation? Trends Ecol Evol 2012, 27:27-39.

83. Turelli M, Barton NH, Coyne JA: Theory and speciation. Trends Ecol Evol 2001, 16:330-343.

84. Slatkin M: Gene flow in natural populations. Ann Rev Ecol Syst 1985 16:393-430.

85. Rossetto M, Allen CB, Thurlby KAG, Weston PH, Milner ML: Genetic structure and bio-climatic modeling support allopatric over parapatric speciation along a latitudinal gradient. BMC Evol Biol 2012, 12:1-16.

86. Rubidge EM, Monahan WB, Parra JL, Cameron SE, Brashares JS: The role of climate, habitat, and species co-occurrence as drivers of change in small mammal distributions over the past century. Global Change Biol 2011, 17:696-708

doi:10.1186/1471-2148-14-34

Cite this article as: Rubidge et al:: Diversification of the Alpine

Chipmunk, Tamias alpinus, an alpine endemic of the Sierra Nevada, California. BMC Evolutionary Biology 2014 14:34.

\section{Submit your next manuscript to BioMed Central and take full advantage of:}

- Convenient online submission

- Thorough peer review

- No space constraints or color figure charges

- Immediate publication on acceptance

- Inclusion in PubMed, CAS, Scopus and Google Scholar

- Research which is freely available for redistribution

Submit your manuscript at www.biomedcentral.com/submit
Biomed Central 